\title{
Survey of general practitioners' attitudes towards psychiatry
}

\author{
Catherine Thompson, ${ }^{1}$ Nisha Dogra, ${ }^{2}$ Robert McKinley ${ }^{3}$
}

The Psychiatrist (2010), 34, 525-528, doi: 10.1192/pb.bp.109.027896

${ }^{1}$ The Speedwell Centre, Bristol; ${ }^{2}$ University of Leicester; ${ }^{3}$ Keele University

Correspondence to Catherine Thompson (catherine.thompson@ awp.nhs.uk)

\begin{abstract}
Aims and method There is a lack of current data regarding attitudes of doctors towards psychiatry. General practitioners (GPs) are increasingly involved in teaching psychiatry, and their attitudes towards psychiatry may affect their ability to promote psychiatry. The main aim of the study is to inform on current attitudes of GPs towards psychiatry as a discipline. The Attitudes Towards Psychiatry (ATP-30) questionnaire was administered to all GPs within Shropshire.
\end{abstract}

Results The response rate was 61\% ( $n=145$ from $N=239)$. The mean score for the ATP-30 was 113.9. An association was found between GP trainer status and higher ATP-30 scores. Positive associations were found between demographic data (age, length of career, postgraduate experience of psychiatry, involvement in undergraduate teaching, GP trainer status) and individual response items on the ATP-30 scale.

Clinical implications General practitioners in Shropshire have a positive attitude towards psychiatry. Associations between demographic data and ATP-30 scores indicate that GPs with more experience of psychiatry and those involved in training may have more positive attitudes. The main limitation of the study is the lack of proven validity of the scale for use in this population. The positive attitude towards psychiatry is consistent with GPs providing the role models needed if they are to be involved to a greater degree with teaching and promoting psychiatry as a career. The need for the development of a more specific tool or an update to the existing tool is discussed.

Declaration of interest None.
The 2007 Royal College of Psychiatrists' campaign Images of Psychiatry had the aim of promoting psychiatry as a 'modern, therapeutic medical discipline which supports recovery'. The campaign's objectives included the development of undergraduate education in psychiatry, raising the proportion of UK medical students choosing psychiatry as their first-choice career to $10 \%$, and reducing the stigma associated with psychiatry and mental illness. One target audience identified was doctors from disciplines other than psychiatry, with the objective of developing a positive and accurate understanding of psychiatry among them. Knowledge of attitudes of doctors from other disciplines towards psychiatry is vital in achieving the objectives listed above and in determining whether changes in attitudes towards psychiatry are needed among the medical profession.

The medical profession's attitudes to psychiatry appear to be negative, although the data are dated. ${ }^{2}$ Recent research on attitudes towards psychiatry within the medical profession itself is limited. ${ }^{3}$ There are more recent studies regarding attitudes of medical undergraduates towards psychiatry, and these suggest unfavourable attitudes towards psychiatry as a career compared with other medical disciplines. ${ }^{4}$ The need for proactive career advice and positive role models at an undergraduate level in order to encourage psychiatry as a career choice has been identified: ${ }^{5}$ only $4-5 \%$ of UK graduates make this choice currently, with $10-11 \%$ being the figure needed in order to sustain recruitment requirements into psychiatry. ${ }^{6}$

To date, undergraduate teaching in psychiatry has largely been by psychiatrists, although, with the introduction of hybrid curricula in medical schools such as that at Keele School of Medicine, ${ }^{7}$ teaching may increasingly be provided in wider settings and by a broader group of professionals. Recent research has focused on undergraduate teaching of psychiatry in the primary care setting and indicates that general practitioners (GPs) may be in a good position to take a more active role in this. ${ }^{8}$ If GPs are to be the positive role models suggested, then their attitudes towards psychiatry may influence both their clinical practice and their ability to teach and promote the specialty.

There is little in the current literature with regard to GPs' attitudes towards psychiatry, and we were unable to find any prevalidated tool for assessing attitudes of the medical profession towards psychiatry. One well-validated tool that has been used extensively in research among undergraduates in measuring attitudes towards psychiatry is the Attitudes Towards Psychiatry (ATP-30) questionnaire. ${ }^{9}$ Although we noted that this tool was designed for an undergraduate population, we felt that the majority of questions remained relevant to a GP population and as such 
the tool has some face validity in our population. Previous use of the tool also allows a useful comparison of GPs' attitudes with published attitudes of student populations.

The primary aim of this study is to inform on current attitudes of GPs towards psychiatry as a discipline.

\section{Method}

Advice was sought from the National Research Ethics Service, which considered the study to be a service evaluation, and therefore ethical approval was not needed. The ATP-30 questionnaire was administered by the internal hospital mail system to all GPs within Shropshire listed within the primary care trusts as partners or salaried GPs $(n=239)$. They were asked to return the questionnaire by the same mail system within 1 month from the date of posting. All entries received by the closing date were entered into a prize draw for $£ 150$.

The ATP-30 consisted of 30 questions regarding attitudes towards psychiatry. Questions were designed to cover eight domains: psychiatric patients, psychiatric illness, psychiatrists, psychiatric knowledge, psychiatric careers choice, psychiatric treatment, psychiatric institutions and psychiatric teaching. These domains were not demonstrated to be valid by its creators, and the instrument has therefore been treated as having validity as a single scale. ${ }^{9}$ All response options were on a 5-point Likert scale (1, agree strongly; 5, disagree strongly). Positively phrased items (questions 4, 5, 9-12, 14, 15, 18, 20, 23, 25, 27-29) were reversed by subtracting the score from 6 . A total score was calculated by adding all item scores (minimum score 30, maximum score 150). A high score indicates a positive attitude towards psychiatry. The ATP-30 scores were not calculated for respondents who omitted questions within the ATP-30. Demographic data (age and gender), years worked as a GP, experience in psychiatry, and current involvement in teaching of undergraduate psychiatry were also collected. All data were analysed descriptively using SPSS package 15.0 for Windows, and univariate analyses were used to find significant associations between ATP-30 scale and item scores and demographic data using the Mann-Whitney and $\chi^{2}$-tests respectively. Variables are reported to be significant if they showed 5\% or more significance level. Corrections were made for type 1 errors using the Bonferroni method.

\section{Results}

The response rate was $61 \%(n=145$ from $N=239)$. The demographic data and results for experience in psychiatry and current involvement in teaching of psychiatry are shown in Table 1 . The modal age range was $46-55$ years (42.1\%), followed by $36-45$ years $(32.1 \%)$; $62.4 \%$ of the respondents were male. The frequency distribution of number of years worked as a GP was fairly equal, but with the largest number in the category of 21 years worked as a GP (35.7\%). Over half (52.1\%) of the GPs had experience in psychiatry only as an undergraduate, while $47.9 \%$ reported postgraduate experience of working in psychiatry. More than a quarter of respondents $(27.8 \%)$ were involved in teaching undergraduate psychiatry, $16.7 \%$ were not involved but would like to be, and $55.6 \%$ were not involved in teaching undergraduate psychiatry and did not wish to be.

\begin{tabular}{|c|c|c|}
\hline & Frequency & Valid \% \\
\hline \multicolumn{3}{|l|}{ Age, years } \\
\hline$<35$ & 20 & 14.3 \\
\hline $36-45$ & 45 & 32.1 \\
\hline $46-55$ & 59 & 42.1 \\
\hline $56-65$ & 16 & 11.4 \\
\hline Total & 140 & 100.0 \\
\hline \multicolumn{3}{|l|}{ Gender } \\
\hline Male & 88 & 62.4 \\
\hline Female & 53 & 37.6 \\
\hline Total & 141 & 100.0 \\
\hline \multicolumn{3}{|l|}{ Time as GP, years } \\
\hline$\leqslant 10$ & 44 & 31.4 \\
\hline$\leqslant 20$ & 46 & 32.9 \\
\hline$\geqslant 21$ & 50 & 35.7 \\
\hline Total & 140 & 100.0 \\
\hline \multicolumn{3}{|l|}{ Experience in psychiatry } \\
\hline Undergraduate & 73 & 52.1 \\
\hline Postgraduate & 67 & 47.9 \\
\hline Total & 140 & 100.0 \\
\hline \multicolumn{3}{|c|}{ Current teaching in psychiatry } \\
\hline Yes & 40 & 27.8 \\
\hline No (would like to) & 24 & 16.7 \\
\hline No (would not like to) & 80 & 55.6 \\
\hline Total & 144 & 100.0 \\
\hline \multicolumn{3}{|l|}{ GP trainer } \\
\hline Yes & 46 & 31.7 \\
\hline No & 99 & 68.3 \\
\hline Total & 145 & 100.0 \\
\hline
\end{tabular}

GP, general practitioner.

Items from the ATP-30 were analysed individually, and a total score was derived from the summation of all items (with reciprocals of positively phrased items) as described earlier. The mean score for the ATP-30 was 113.9 (range 87138, standard deviation 9.4 for the 134 participants for whom it could be calculated). Data were distributed normally, with no outliers; if 90 is considered to be the logical neutral point of the scale, then the results indicate a generally positive attitude towards psychiatry (Fig. 1).

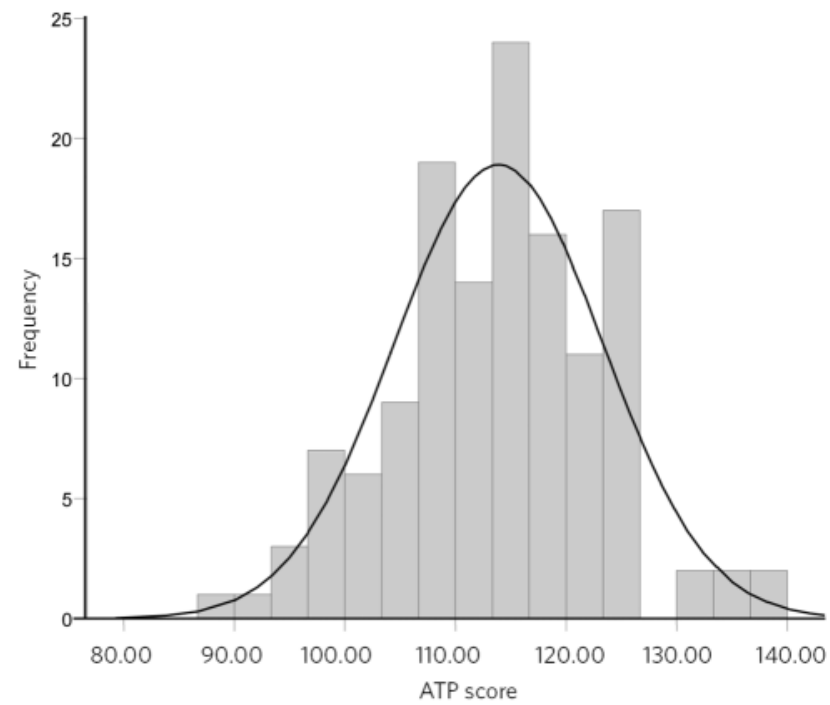

Fig 1 Attitudes Towards Psychiatry (ATP-30) scores. Mean score 113.89 (s.d. =9.43), $n=134$. 
No significant associations were found between the demographic variables of age, gender, number of years worked, experience in psychiatry, teaching involvement in psychiatry and ATP-30 scores. There was an association found between GP trainers and higher ATP-30 scores (GP trainer: $n=40$, mean rank 77.58; non-GP trainer: $n=94$, mean rank 63.21; Mann-Whitney $U$-test statistic 1477.0, $P=0.050$ ), but this was not significant when the Bonferroni correction for multiple testing $(n=6)$ was applied (threshold $P=0.008$ ).

The three items from the ATP-30 scale that showed the most variability in responses and highest frequencies of negative responses are shown in Table 2, with $71.8 \%$ of respondents disagreeing or strongly disagreeing with item number 4 ('I would like to be a psychiatrist'), 53.5\% agreeing or strongly agreeing with item number 21 ('If I were asked what I considered to be the three most exciting specialties, psychiatry would be excluded') and $61.6 \%$ disagreeing or strongly disagreeing with item number 23 ('Psychiatry is the most important part of the medical school curriculum'). Responses for all 30 items from the scale are shown in online Table DS1.

Significant cross-tabulations made for associations between demographic data and individual response items on the ATP-30 scale are shown in Table 3. These were not significant when the Bonferroni correction for multiple testing $(n=180)$ was applied (threshold $P=0.0003)$.

\section{Discussion}

The main finding from this study is that GPs in Shropshire have a generally positive attitude towards psychiatry. The positive attitude was independent of age, gender, number of years worked in general practice, experience in psychiatry, and involvement of the GP in undergraduate teaching in psychiatry. General practitioners who were trainers on the GP vocational training scheme may have higher scores. There were negative attitudes seen on individual items for the ATP-30, which appear to have some face validity. It should be remembered that the ATP-30 does not have proven validity for individual items (even in the population for which it was developed). It is, however, interesting to note that over $50 \%$ of our sample would exclude psychiatry from the three most exciting medical specialties.

There may be associations between individual scale item correlations and demographic data: older GPs, those who had worked for longer, those with postgraduate experience in psychiatry, those currently involved in

\begin{tabular}{|c|c|c|c|}
\hline Item & Response & Frequency & Valid \% \\
\hline 4 ('I would like to be a psychiatrist') & $\begin{array}{l}\text { Strongly agree/agree } \\
\text { Neutral } \\
\text { Disagree/strongly disagree } \\
\text { Total }\end{array}$ & $\begin{array}{r}15 \\
26 \\
104 \\
145\end{array}$ & $\begin{array}{r}10.4 \\
17.9 \\
71.7 \\
100.0\end{array}$ \\
\hline $\begin{array}{l}21 \text { ('If I were asked what I considered to be the three most exciting } \\
\text { medical specialties, psychiatry would be excluded') }\end{array}$ & $\begin{array}{l}\text { Strongly agree/agree } \\
\text { Neutral } \\
\text { Disagree/strongly disagree } \\
\text { Total }\end{array}$ & $\begin{array}{r}77 \\
26 \\
41 \\
144\end{array}$ & $\begin{array}{r}53.5 \\
18.1 \\
28.4 \\
100.0\end{array}$ \\
\hline $\begin{array}{l}23 \text { ('Psychiatry is the most important part of the medical school } \\
\text { curriculum in medical schools') }\end{array}$ & $\begin{array}{l}\text { Strongly agree/agree } \\
\text { Neutral } \\
\text { Disagree/strongly disagree } \\
\text { Total }\end{array}$ & $\begin{array}{r}10 \\
45 \\
88 \\
143\end{array}$ & $\begin{array}{r}7.0 \\
31.5 \\
61.5 \\
100.0\end{array}$ \\
\hline
\end{tabular}

\begin{tabular}{|c|c|c|c|c|}
\hline $\begin{array}{l}\text { Demographic } \\
\text { variable }\end{array}$ & ATP item number & $\chi^{2}$ & $\begin{array}{l}\text { Degrees of } \\
\text { freedom }\end{array}$ & $P$ \\
\hline Age & $\begin{array}{l}14 \text { ('With the forms of treatment now at hand, most psychiatric } \\
\text { patients now improve') } \\
25 \text { ('In recent years, psychiatric treatment has become quite } \\
\text { effective') }\end{array}$ & $\begin{array}{r}6.945 \\
10.565\end{array}$ & $\begin{array}{l}2 \\
2\end{array}$ & $\begin{array}{l}0.031 \\
0.005\end{array}$ \\
\hline $\begin{array}{l}\text { Number of years worked } \\
\text { as a GP }\end{array}$ & 11 ('Psychiatry is a respected branch of medicine') & 9.821 & 4 & 0.044 \\
\hline Experience in psychiatry & $\begin{array}{l}15 \text { ('Psychiatrists tend to be at least as stable as the average } \\
\text { doctor') } \\
21 \text { negatively phrased item ('If I were asked what I considered to be } \\
\text { the three most exciting medical specialties, psychiatry would be } \\
\text { excluded') }\end{array}$ & 14.081 & 2 & 0.001 \\
\hline $\begin{array}{l}\text { Current teaching of } \\
\text { psychiatry }\end{array}$ & $\begin{array}{l}30 \text { negatively phrased item ('Psychiatry is so amorphous it cannot } \\
\text { really be taught effectively') }\end{array}$ & 9.769 & 4 & 0.045 \\
\hline GP trainer status & $\begin{array}{l}10 \text { ('The majority of students report that their psychiatric } \\
\text { undergraduate training has been valuable') } \\
28 \text { ('The practice of psychiatry allows the development of really } \\
\text { rewarding relationships with people') }\end{array}$ & $\begin{array}{l}8.063 \\
6.293\end{array}$ & 2 & $\begin{array}{l}0.018 \\
0.043\end{array}$ \\
\hline
\end{tabular}

GP, general practitioner. 
undergraduate teaching, and GP trainers showed more positive attitudes on certain single-scale items. This may indicate that GPs who have had a longer career in general practice, GP trainers and GPs involved in undergraduate teaching value psychiatry more. These interpretations are tentative, as the scale has not been validated for individual items and threshold $P$ values were not reached when corrections were made for multiple testing.

The demographic data shows a mature GP population, with $53.5 \%$ aged 46 years or over and $35.7 \%$ listed as working for 21 years or more in general practice. Postgraduate experience in psychiatry was relatively high, at $47.9 \%$. It is interesting to note that $55.6 \%$ of GPs were not involved in teaching undergraduate psychiatry and did not wish to be, while $16.5 \%$ were not involved but would like to be. This may indicate an underused resource for student placements in Shropshire, and further exploration is warranted by local undergraduate course organisers, particularly as Shropshire has recently developed formal links with Keele School of Medicine. Shropshire has a relatively stable GP population, with high numbers of older GPs and low historic involvement with undergraduate teaching; this should be considered when generalising attitudes towards psychiatry to the wider GP population. The positive attitudes seen in our sample may reflect opinion regarding the quality of local mental health services; it is notable that Healthcare Commission reports rated Shropshire community mental health services as good ${ }^{10}$ and Shropshire acute in-patient mental health services as excellent. ${ }^{11}$

The study has other limitations. There is the possibility of a response bias: $61 \%$ of GPs responded, and those with unfavourable attitudes towards psychiatry may not have wished to participate in the study. There is also a question of validity of the tool for use in the chosen population. The ATP-30 was designed specifically for a medical student population, and a few of the questions did not relate well to practising doctors. The items listed in Table DS1 with particularly negative responses may not be valid for established practitioners and so may bias the results. The tool was designed in 1983 and some of the questions appear dated in their terminology. For example, question 23, which asks whether psychiatry is the most important part of a medical school curriculum, does not match contemporary approaches to curriculum development, and disagreement with this statement by GPs would not necessarily indicate a negative attitude to psychiatry; a positive response may indicate the tool's insensitivity rather than positive attitudes towards psychiatry. The ATP-30 was devised to measure the broad concept of 'attitudes towards psychiatry as a discipline'. It is, however, possible that the attitudes shown here are reflecting something other than this. For example, practitioners' responses may reflect positive attitudes towards mental health rather than psychiatry as a whole. The scale does, however, by incorporating the eight domains stated in the Method, attempt to generate a broader opinion on psychiatry as a discipline. Notwithstanding considerations of validity, sensitivity and specificity, we consider that the comparisons with previous studies allowed by using the ATP-30 were more valuable than designing a new tool with no historical comparison data.
The mean ATP-30 score of 113.9 for this group of GPs compares favourably with scores from previous studies in sixth-form students (mean ATP-30 score 110.0), ${ }^{5}$ psychiatric residents (mean ATP-30 score 116.33) and medical students (mean ATP-30 score 103.76), ${ }^{4}$ and with a study showing preand post-psychiatry attachment mean ATP-30 scores in medical students of 102.6 and 107.7 respectively. ${ }^{12}$ This is reassuring, given the importance of psychiatry within the specialty, which may promote a more positive attitude among GPs than could be expected in other specialties. Further studies looking at the attitudes of doctors within other specialties would be useful and may also help to determine whether the ATP-30 is a sensitive discriminatory measure with regard to attitudes in practising doctors or whether a new tool needs to be designed for this purpose.

\section{Funding}

This study received partial funding from the Royal College of Psychiatrists' Images of Psychiatry campaign.

\section{About the authors}

Catherine Thompson is a consultant in general adult psychiatry in the Bristol East Support and Recovery Team within the Avon and Wiltshire Mental Health Partnership NHS Trust. Nisha Dogra is a senior lecturer in child and adolescent psychiatry at University of Leicester. Robert McKinley is Professor of Academic General Practice at Keele University.

\section{References}

1 Royal College of Psychiatrists. Images of Psychiatry. Royal College of Psychiatrists, 2009 (http://www.rcpsych.ac.uk/campaigns/previous campaigns/imagesofpsychiatry.aspx)

2 Harris C. Medical stereotypes. BMJ 1981; 283: 1676-7.

3 Buchanan A, Bhugra D. Attitude of the medical profession to psychiatry. Acta Psychiatr Scand 1992; 85: 1-5.

4 Malhi GS, Parker GB, Parker K, Carr VJ, Kirkby KC, Yellowlees P, et al. Attitudes toward psychiatry among students entering medical school. Acta Psychiatr Scand 2003; 107: 424-9.

5 Maidment R, Livingston M, Katona M, Whittaker E, Katona C. Carry on shrinking: career intentions and attitudes to psychiatry of prospective medical students. Psychiatr Bull 2003; 27: 30-32.

6 Goldacre MJ, Turner G, Fazel S, Lambert T. Career choices for psychiatry: national surveys of graduates of 1974-2000 from UK medical schools. Br J Psychiatry 2005; 186: 158-64.

7 Keele University. Undergraduate Medicine 2011. Keele University, 2009 (http://www.keelemedicalschool.org.uk/keele_medical_school/resources/ MedSch_Brochure.pdf).

8 Walters K, Raven P, Rosenthal J, Russell J, Humphrey C, Buszewicz M. Teaching undergraduate psychiatry in primary care: the impact on student learning and attitudes. Med Ed 2007; 41: 100-8.

9 Burra P, Kalin P, Leichner P, Waldron JJ, Handforth JR, Jarrett FJ, et al. The ATP-30: a scale for measuring medical students' attitudes to psychiatry. Med Ed 1982; 16: 31-8.

10 Commission for Healthcare Audit and Inspection. No Voice, No Choice: A Joint Review of Adult Community Mental Health Services in England. Commission for Healthcare Audit and Inspection, 2007.

11 Commission for Healthcare Audit and Inspection. The Pathway to Recovery: A Review of NHS Acute Inpatient Mental Health Services. Commission for Healthcare Audit and Inspection, 2008.

12 McFarland M, Noble L, Livingston G. The effect of a psychiatric attachment on students' attitude to pursue psychiatry as a career. Med Ed 2003; 37: 447-54. 